\title{
Conflitos de Leis E JuRisdições nas Transações Celebradas a PARTIR dA BlockChain
}

\author{
CONFLICTS OF LAW AND JURISDiCTION ON \\ BlockCHAIN TRANSACTIONS
}

\section{Conflictos de Leyes y JuRisdicciones en Transacciones Celebradas desde Blockchain}

\author{
Michele Alessandra Hastreiter \\ Marcia Carla Pereira Ribeiro ${ }^{* *}$
}

\begin{abstract}
1Introdução. 2 Breves considerações sobre as principais características da blockchain. 3 O Código precisa de uma lei? 4 Conflitos de leis e jurisdições na blockchain. 4.1 Conflito de jurisdições na blockchain. 4.2 Conflito de leis na blockchain. 5 O Conflito de leis e jurisdições sob a ótica de uma governança peer to peer. 6 Considerações Finais. Referências.
\end{abstract}

\section{RESUMO}

Contextualização: A tecnologia conhecida como blockchain permite a celebração de negócios jurídicos internacionais per se, uma vez que seu funcionamento se pauta na lógica descentralizada, na qual seus diferentes "nós" estão distribuídos em computadores de todo o mundo. No entanto, localizar uma transação feita através da blockchain por meio do raciocínio clássico do Direito Internacional Privado é tarefa desafiadora, o que traz questionamentos quanto à forma de solucionar o conflito de leis e jurisdições em relações jurídicas transnacionais.

\footnotetext{
" Doutoranda em Direito pela Universidade Federal do Paraná. Mestre em Direito pela Pontifícia Universidade Católica do Paraná. Especialista em Direito, Logística e Negócios Internacionais. Advogada e Administradora Internacional de Negócios. Professora de Direito Internacional Público e Privado no Centro Universitário Curitiba (UNICURITIBA). Curitiba - PR - BR. E-mail: <michele.hastreiter@gmail.com>. https://orcid.org/0000-0002-1476-3581

** Professora Titular de Direito Societário na Pontifícia Universidade Católica do Paraná - PUCPR. Professora Associada de Direito Empresarial na Universidade Federal do Paraná - UFPR. Pós-doc pela FGVSP, pela Faculdade de Direito da Universidade de Lisboa e pela Université Paris 1 Panthéon Sorbonne. Pesquisadora Conv.Université de Montréal - CA. Advogada. Curitiba - PR - BR. E-mail: <mcarlaribeiro@uol.com.br>.https://orcid.org/0000-0001-7540-5406
} 
Objetivo: $O$ objetivo deste artigo é apresentar as dificuldades para identificação da corte competente e do elemento de conexão aplicável aos conflitos internacionais potencialmente emergentes da tecnologia, bem como apontar possíveis caminhos para uma solução.

Metodologia: A pesquisa utiliza-se do método dedutivo; quanto ao procedimento, é uma pesquisa bibliográfica que analisa estudos e artigos científicos sobre o tema.

Resultados: A pesquisa conclui que a aplicação dos critérios clássicos para solucionar os conflitos de leis no espaço na tecnologia requer cuidados específicos e sugere que a própria tecnologia peer to peer pode trazer alternativas viáveis para uma maior segurança jurídica na solução de conflitos emergentes da tecnologia.

Palavras-chave: blockchain; direito internacional privado; peer to peer; jurisdição; conflito de leis.

\section{ABSTRACT}

Background: The technology known as blockchain allows private relations that are international per se, since its operation is based on decentralized logic, in which its different "nodes" are distributed in computers all over the world. However, to locate a transaction made through blockchain through the classical reasoning of Private International Law is a challenging task, which brings questions about how to address the matter of jurisdiction and choice of law in those legal relations.

Objective: The objective of this article is to present the difficulties in identifying the competent court and the connecting factor applicable to international conflicts potentially arising from the technology, as well as to point out possible paths for a solution.

Method: The research uses the deductive method; as for the procedure, it is a bibliographical research that analyzes studies and scientific articles on the subject.

Results: The research concludes that the application of classical criteria to solve conflicts of laws matters in the blockchain requires specific care and suggests that peer to peer technology itself can bring viable alternatives for greater legal security in the solution of conflicts emerging from technology.

Keywords: blockchain; private international law; peer to peer; jurisdiction; conflict of laws.

\section{RESUMEN}

Contextualización: La tecnología conocida como blockchain permite la realización de transacciones legales internacionales per se, ya que su funcionamiento se basea en una 
lógica descentralizada, en la que sus diferentes "nodos" están distribuidos en ordenadores de todo el mundo. Sin embargo, ubicar una transacción realizada a través de blockchain mediante el razonamiento clásico del Derecho Internacional Privado es una tarea desafiante, que trae consigo preguntas sobre cómo resolver el conflicto de leyes y jurisdicciones en las relaciones jurídicas transnacionales.

Objetivo: El objetivo de este artículo es presentar las dificultades para identificar el tribunal competente y el elemento de conexión aplicable a los conflictos internacionales potencialmente emergentes de la tecnología, así como señalar las posibles vías de solución.

Método: La investigación utiliza el método deductivo; en cuanto al procedimiento, se trata de una investigación bibliográfica que analiza estudios y artículos científicos sobre el tema.

Resultados: La investigación concluye que la aplicación de los criterios clásicos para resolver los conflictos de leyes en el espacio en la tecnología requiere un cuidado específico y sugiere que la propia tecnología peer to peer puede aportar alternativas viables para una mayor seguridad jurídica en la solución de los conflictos emergentes de la tecnología.

Palabras clave: blockchain; derecho internacional privado; peer to peer; jurisdicción; conflicto de leyes.

\section{INTRODUÇÃO}

Este trabalho pretende analisar a tecnologia blockchain sob o prisma do Direito Internacional Privado - isto é, com enfoque no conflito de leis e jurisdições que permeiam as transações celebradas via blockchain. Trata-se de tema frequentemente negligenciado nas pesquisas sobre o assunto, dada a crença de que a tecnologia representaria uma alternativa aos sistemas jurídicos estatais.

No entanto, a lógica binária da computação pode até amparar os silogismos da norma ("se acontece X, então Y"). Contudo, ignora o caráter valorativo do Direito. Assim, ainda que um contrato seja autoexecutável e dispense uma execução forçada e judicial, ainda há questões fundamentais a serem respondidas pelo Direito, como a validade - e até, por que não, justiça - do conteúdo programado. Um programa de computador não pode ser encarregado de dizer se a conclusão $\mathrm{Y}$, decorrente da ocorrência do evento $\mathrm{X}$ é correta, justa e adequada aos objetivos definidos por uma sociedade na regulação de seu convívio.

Dessa forma, nota-se que a tecnologia da blockchain não prescinde do Direito, e, a partir do momento em que se reconhece tal fato, faz-se necessário entender qual o Direito 
que será empregado para responder as demandas jurídicas emergentes a partir da blockchain. Isto porque os sistemas jurídicos seguem lógicas territoriais e as soluções de Direito Privado não são uniformes ao redor do globo. No entanto, o caráter a-nacional da blockchain, que atua por meio de "nós" distribuídos em uma rede descentralizada, torna difícil localizá-la no espaço geográfico.

Determinar qual sistema legal fornecerá respostas às demandas jurídicas que possuem contato com mais de um sistema jurídico normativo é assunto que tradicionalmente se insere no escopo do Direito Internacional Privado - ramo do Direito encarregado de solucionar os conflitos de leis no espaço. O Direito Internacional Privado clássico, porém, é pautado em critérios territoriais: busca-se localizar a relação jurídica no espaço - o que é feito por meio dos chamados "elementos de conexão", que visam encontrar a "sede" da relação jurídica, na terminologia usada por Savigny - para então definir a qual Direito ela pertence. Tal lógica é desafiada pela virtualidade que a Internet traz às relações - e isto se aprofunda com a lógica de registros distribuídos (Distributed Ledger Technology - DLT) que permeia a blockchain.

Assim, este trabalho se inicia esclarecendo em linhas gerais no que consiste a tecnologia blockchain e, na sequência, aborda brevemente a necessidade de vinculação das transações a um panorama normativo estatal, contestando a afirmação de entusiastas da tecnologia de que o código seria a lei da blockchain e que este seria autossuficiente e capaz de concretizar as transações de maneira independente de um sistema legal. Uma vez reconhecida a necessidade de um Direito a regular à blockchain, passa-se ao objeto central deste trabalho, qual seja, entender qual o Direito nacional - dentre os possíveis que deverá fornecer as respostas jurídicas as questões emergentes da tecnologia.

O trabalho busca, por meio de uma revisão bibliográfica, verificar a possibilidade de conciliar os critérios tradicionais do Direito Internacional Privado ao inovador universo das transações na blockchain. Por fim, evidenciando a interconexão entre a blockchain e o Direito Internacional Privado, o trabalho se encerra abordando como os arranjos institucionais peer to peer também podem ajudar a solucionar os problemas de Direito Internacional Privado - inclusive, os criados pela própria tecnologia.

\section{BREVES CONSIDERAÇÕES SOBRE AS PRINCIPAIS CARACTERÍSTICAS DA BLOCKCHAIN}

A tecnologia conhecida como "blockchain" foi inventada em 2008 por Satoshi Nakamoto $^{1}$, que criou um protocolo que garante a integridade de dados trocados diretamente entre duas partes, sem a necessidade de intermediários. Em linhas gerais,

\footnotetext{
${ }^{1}$ O nome é, na realidade, um pseudônimo para a pessoa ou grupo de pessoas que criou a bitcoin (TAPSCOTT; TAPSCOTT, 2016, p. 5).
}

63• R. Opin. Jur., Fortaleza, ano 20, n. 33, p.60-82, jan./abr. 2022 
trata-se de um software de open source que grava transações em uma espécie de livro-razão contábil global (a chamada blockchain). A blockchain não fica armazenada em uma database central, mas sim distribuída em computadores de voluntários ao redor do mundo, razão pela qual também é chamada de Distributed Ledger Technology (DLT).

A primeira aplicação prática da tecnologia foram as criptomoedas ${ }^{2}$, já que o protocolo resolveu problemas de confiança para transações financeiras eletrônicas utilizando a tecnologia peer to peer e, assim, eliminando a necessidade de terceiros (como uma instituição financeira e, até mesmo, o Estado). As criptomoedas são, também, usadas como incentivo para os voluntários que atuam na autenticação das transações feitas por meio da blockchain (SINCLAIR; DE FILIPPI; POTTS, 2016).

Considerando que a tecnologia oferece um mecanismo de transferência de ativos entre duas partes em qualquer lugar do mundo - bastando para isso que as partes envolvidas tenham acesso à Internet - seu uso não precisa estar restrito à transferência de criptomoedas. Os ativos transferidos também podem ser objetos do mundo real (como ouro, ações e até imóveis) (LEHMAN, 2019, p. 2).

Há, ainda, um amplo espectro de aplicações para a tecnologia ainda em desenvolvimento. Para citar alguns exemplos emblemáticos, pode-se dizer que ela permite a desburocratização governamental (como já acontece na Estônia ${ }^{3}$ ) e viabiliza uma série de smart contracts (protocolos de transação computadorizados que executam os termos do contrato automaticamente) (TAPSCOTT; TAPSCOTT, 2016).

Segundo Lehman (2019, p. 2), a confiabilidade da blockchain é resultado de suas três características principais: o fato de operar a partir de pseudônimos, a resiliência e a imutabilidade. A primeira característica é um mecanismo importante para a proteção da privacidade das partes envolvidas, já que as transações ficam registradas em um livrorazão público, mas sem que a identidade das partes seja revelada. O autor considera, também, a tecnologia resiliente, uma vez que o livro-razão no qual ela se baseia está distribuído em um enorme número de "nós" espalhados em diferentes computadores, os quais não podem ser alvo de um ataque hacker todos ao mesmo tempo. Isso também contribui para a imutabilidade da transação envolvida, uma vez que a transferência não pode ser desfeita depois de ter sido registrada na blockchain.

Essas três características fazem que a tecnologia funcione como uma garantia de segurança e confiabilidade às transações, o que pode ser útil em diversos cenários. Por isso, Sinclair, De Filippi e Potts (2016) a classificam não apenas como uma nova

\footnotetext{
2 Moedas eletrônicas que diferem das tradicionais por não serem controladas por nenhum país (TAPSCOTT; TAPSCOTT, 2016, p. 5).

${ }^{3} \mathrm{O}$ país trabalho com uma espécie de identidade digital criada na blockchain, que permite acesso a diferentes serviços públicos. Sobre o tema, ver em: IRIS, Blockchain and e-Government: The Estonian experience and the first Brazilian initiatives. Disponivel em: https://irisbh.com.br/en/blockchain-ande-government-the-estonian-experience-and-the-first-brazilian-initiatives/. Acesso em: 5 jan. 2020. (TAPSCOTT; TAPSCOTT, 2016, p. 197 e ss.).
} 
tecnologia capaz de reduzir custos de produção, mas como uma nova estrutura de governança que promoverá eficiência organizacional a partir da redução dos custos de transação ${ }^{4}$.

Para Williamson (1985), as estruturas de governança seriam os diferentes mecanismos de coordenação usados para a redução dos custos de transação. $O$ autor elenca três alternativas possíveis: os mercados, as hierarquias e as estruturas híbridas (firms, markets and relational contracts). Sustenta-se, assim, que a blockchain pode competir com as firmas, os mercados e os contratos relacionais como alternativas institucionais para a coordenação das ações de grupos de pessoas, justamente por serem ferramentas capazes de fabricar consensos sobre fatos instrumentais à coordenação econômica, um papel historicamente dominado pelos governos e pelas grandes empresas (SINCLAIR; DE FILIPPI; POTTS, 2016).

A inovação que a blockchain traz às instituições faz que a tecnologia seja considerada, por alguns ${ }^{5}$, até mesmo, como uma alternativa ao Direito como um todo. Essa ideia, porém, não resiste a uma análise mais detida.

\section{O CÓDIGO PRECISA DE UMA LEI?}

Segundo Ruhl (2020), o assunto da lei aplicável às transações feitas a partir da blockchain (criptomoedas e smart contracts) é negligenciado em razão do entendimento de que a tecnologia envolvida na blockchain não requer um sistema legal para operar. $\mathrm{O}$ fato de os contratos serem autoexecutáveis tornaria desnecessária qualquer interferência jurídica.

Essa possibilidade, trazida pela blockchain, fortalece o coro libertário e, de certa forma, anarquista ${ }^{6}$, que já permeia os debates sobre a regulação da Internet desde sua origem. O bordão utilizado entre os entusiastas da tecnologia é "Code is law" (o código é a lei) ${ }^{7}$. Não obstante, um código é um código. Ele apenas executa o que foi programado

\footnotetext{
${ }^{4}$ Os custos das transações econômicas fazem parte das tradicionais pesquisas da Nova Economia Institucional, que parte do pressuposto de que o principal propósito das instituições econômicas do capitalismo é economizar em custos de transação. Nesse sentido, ver em: Williamson (1985).

${ }^{5}$ Destaca-se, nesse sentido, Alexander Savelyev, que afirma: “Strictly speaking, smart contracts don't have a need in a legal system to exist: they may operate without any overarching legal framework. De facto, they represent a technological alternative to the whole legal system." (SAVELYEV, 2016, online).

${ }^{6}$ Lehmann afirma que existem, de fato, grupos anarquistas de "cypherpunks" e "crypto rebels" que defendem a tecnologia da blockchain como uma garantia das liberdades individuais frente ao "Big brother" do Estado. Sobre isso, ver em: Lehmann (2019, p. 6).

${ }^{7}$ A expressão dá título ao primeiro capítulo da clássica obra sobre o tema de Lawrence Lessig (publicada originalmente em 1999). A intenção do autor, contudo, não era a de defender um caráter anti-Direito para a tecnologia, pois Lessig defende justamente a perspectiva contrária (de que a arquitetura da Internet requer intervenção estatal). Ao usar a expressão, o autor ilustra que o surgimento da Internet (e do ciberespaço) se tornou o novo alvo da utopia libertária desde que a euforia pós-comunista na Europa começou a se enfraquecer. Seria este o local onde a liberdade do indivíduo, sem as amarras do
}

65• R. Opin. Jur., Fortaleza, ano 20, n. 33, p.60-82, jan./abr. 2022 
para fazer. Faz-se necessário um sistema que permita auferir a validade - e, até mesmo, dar espaço as considerações de justiça - às transações realizadas através do código ${ }^{8}$.

Nesse sentido, Ruhl afirma que

um olhar mais cuidadoso, no entanto, revela que os smart contracts não são - e
não devem ser - independentes do Direito. De fato, enquanto talvez seja
verdade que os smart contracts não precisam de um sistema legal para operar
ou executar obrigações legais, parece haver poucas dúvidas de que os smart
contracts dependem de um sistema legal para determinar se há alguma
obrigação legal a ser executada, para início de conversa. Isto porque o smart
contract sozinho - como um pedaço de código - não tem meios para saber se
uma obrigação legal válida foi criada. Ele não tem sequer meios para saber se
as partes que decidiram usar o smart contract consentiram validamente. Tudo
que o smart contract pode fazer é o que disseram a ele que fizesse. No entanto,
poder fazer algo, não significa que fazê-lo é correto ou legal. O código não é a
lei. E não deve ser (RUHL, 2020, p. 4). ${ }^{9}$

Ademais, diversas são as situações que podem demandar a intervenção do Direito, mesmo diante de obrigações supostamente autoexecutáveis. $O$ roubo de criptomoedas, uma transferência de criptomoeda feita com um vício de vontade (erro, dolo ou coação ${ }^{10}$ ), um smart contract cujos termos não corresponderam à expectativa das partes, ou cuja execução automática tornou-se impossível por uma circunstância material concreta (ex. morte ou insolvência do devedor) e, ainda, situações que afetam terceiros, como a forma pela qual criptomoedas devem ser transferidas para herdeiros ou credores (em caso de morte ou insolvência do seu detentor), são apenas alguns exemplos (GUILLAUME, 2019, p. 75). Preocupações de interesse público - como evitar que a

Estado, poderia finalmente reinar. Isto porque a regulação da Internet pelos governos seria impossível. No entanto, o ciberespaço passa a ser um espaço fortemente regulado, ainda que a forma de regulação não seja idêntica à regulação tradicionalmente feita pelo Estado por meio do Direito. (Nesse sentido, ver em: Lessig (2006).

${ }^{8}$ Lawrence Lessig também enfatiza a importância dos valores a serem buscados na regulação da Internet. Nesse sentido, afirma "code is never found; it is only ever made, and only ever made by us (...) But by whom and with what values? That is the only choice we have left to make". (LESSIG , 2006, p. 6).

9 "A closer look, however, reveals that smart contracts are not - and should not - be independent of the law.10 In fact, while it might be true that smart contracts do not need a legal system to operate and to execute legal obligations, there can be little doubt that smart contracts depend on a legal system to determine whether there is any enforceable legal obligation to begin with. This is because the smart contract itself - as a piece of code - does not have the means of knowing whether an enforceable legal obligation has been validly created. It does not even have the means of knowing whether the parties who decide to make use of a smart contract have validly agreed to do so. All that a smart contract can do is to do what it has been told to do. However, the mere power to do something, does not mean that doing it, is right or legal. Code is not law. And it should not" (Tradução livre)

${ }^{10} \mathrm{Tal}$ hipótese, segundo Lehmann, está longe de ser fantasiosa, já que há registros de chantagens feitas online, demandando pagamentos em bitcoins para evitar a publicação de informações privadas na Internet. (LEHMANN, 2019, p. 7). 
tecnologia seja usada para lavagem de dinheiro e a evasão fiscal, por exemplo - também requerem uma regulação estatal (LEHMAN, 2019, p. 3).

O que se nota, portanto, é que, por mais automatizadas que sejam as transações e ainda que o potencial de conflitos possa ser reduzido por meio da ferramenta, ela não eliminará a necessidade de um sistema normativo como referencial. No entanto, uma vez que a necessidade do Direito esteja estabelecida, o desafio passa a ser identificar a qual sistema jurídico a transação - que ocorre simultaneamente em diversos computadores em lugares diferentes do mundo - pertence.

\section{CONFLITO DE LEIS E JURISDIÇÕES NA BLOCKCHAIN}

Para Savelyev (2016), a blockchain tornaria obsoleto o debate sobre o conflito de leis e jurisdições, justamente por não precisar de um sistema legal para operar. Isso faria que fossem inexistentes as colisões entre diferentes sistemas jurídicos: a blockchain tornaria concreto um Direito Contratual Uniforme a partir da linguagem universal da matemática.

Como já se observou, porém, é simplista pressupor que os smart contracts operariam plenamente dentro de ambientes virtuais, de modo completamente desconectado do mundo real e dos sistemas jurídicos estatais. Aceitando a necessidade de um Direito para regular as transações celebradas via blockchain, o potencial para inserir a tecnologia nos debates de Direito Internacional Privado torna-se evidente.

Isso porque o uso da blockchain é parte do uso mais amplo da Internet, ferramenta de aspiração universal, desmaterializada e intrinsecamente transacional (GUILLAUME, 2019). Seu uso não conhece fronteiras - o que possibilitou uma grande disseminação dos contratos internacionais. Na blockchain, por sua vez, a internacionalidade lhe é intrínseca, já que os diferentes "nós" da blockchain são armazenados em computadores diferentes - os quais, é lógico supor, não estarão todos em um mesmo Estado ${ }^{11}$.

Isto faz que as transações celebradas pela blockchain se tornem internacionais per se, independentemente da localidade das partes envolvidas (as quais, por características

\footnotetext{
${ }^{11}$ Para Gisela Ruhl, a presença dos "nós” em diferentes computadores é, por princípio, suficiente para que se investigue a transação sob a ótica do Direito Internacional Privado. Isso porque, na visão majoritária da doutrina, não são necessários muitos requisitos para que um contrato seja considerado internacional; até o idioma em que foi redigido pode desencadear questionamentos sobre isto. Analisar o tema sob a ótica do Direito Internacional Privado, contudo, não significa dizer que um direito estrangeiro será aplicado. Significa dizer apenas que é necessário checar qual o direito aplicável - que pode muito bem, ao fim e ao cabo, vir a ser o nacional (RUHL, 2020, p. 7).
}

67• R. Opin. Jur., Fortaleza, ano 20, n. 33, p.60-82, jan./abr. 2022 
intrínsecas à tecnologia, podem, até mesmo ter a sua identidade $\operatorname{preservada}^{12}$ - e consequentemente sua nacionalidade ou domicílio também - compartilhando apenas dados essenciais para a execução da transação ${ }^{13}$ ). Ademais, ao menos nas transações que envolvem criptomoedas, é bastante comum que as partes estejam em países diferentes.

Não há, todavia, um Direito Uniforme para regular as transações digitais e, ainda que alguns esforços nesse sentido estejam acontecendo (mormente pelo trabalho de organismos internacionais, como a UNIDROIT ${ }^{14}$ e a UNCITRAL ${ }^{15}$ ), é razoável pressupor que uma uniformização completa é um objetivo ainda distante. Assim, as normas conflituais de Direito Internacional Privado permanecem importantes. A adequação dos modelos existentes, porém, é questão controvertida, especialmente diante do caráter territorial que permeia a disciplina ao longo dos últimos dois séculos.

$\mathrm{Na}$ maior parte do mundo, os pilares centrais do Direito Internacional Privado baseiam-se, ainda, no modelo clássico elaborado no Século XIX por Friedrich Carl Von Savigny. $\mathrm{O}$ autor propôs basicamente a possibilidade de localizar as relações jurídicas no espaço, encontrando sua "sede", a qual poderia ser identificada pela natureza própria da relação em análise (SAVIGNY, 2004, p. 15).

A proposta savignyana, contudo, era de que a resposta ao conflito de leis fosse universal, de modo que a decisão a ser tomada no caso de colisão de leis deveria ser sempre a mesma, independentemente do local onde a sentença seria proferida (SAVIGNY, 2004, p. 49). Contudo, essa perspectiva não resistiu à inclusão do Direito Internacional Privado nos processos de codificação nacionais - e os anos seguintes testemunharam uma nacionalização da disciplina, com a fragmentação e diversificação das respostas aos conflitos de leis nos diferentes sistemas jurídicos nacionais ${ }^{16}$.

A situação atual, segundo Araújo (2011, p. 46), compromete a segurança jurídica de três formas: i) como cada Estado possui regras próprias para solução do conflito de leis, é possível que as partes proponham a mesma ação em mais de um Estado e recebam

\footnotetext{
${ }^{12}$ Uma das características da Blockchain é a possibilidade de operar por meio de pseudônimos, fazendo que as transações fiquem disponíveis ao público, mas sem que a identidade das partes seja revelada. Nesse sentido, ver em Lehman (2019, p. 4).

${ }^{13}$ Nos dizeres de Tapscott e Tapscott, "Imagine a new era of Internet where your personal avatar manages and protects the contents of your black box". (TAPSCOTT; TAPSCOTT, 2016, p. 15).

${ }^{14} \mathrm{O}$ tema "Digital Assets and Private Law" foi incluído no Work Programme 2020-2022 da organização. Disponível em: https://www.unidroit.org/english/governments/assemblydocuments/2019. 78session/ag-78-03-e.pdf. Acesso em: 12 jan. 2021.

${ }^{15}$ A UNCITRAL tem elaborado leis modelos para transações eletrônicas desde 1996. Nesse sentido, ver em: https://uncitral.un.org/en/texts/ecommerce/modellaw/electronic_commerce .

${ }^{16}$ Sobre o tema, sustenta Nádia de Araújo que "as doutrinas do século XIX são todas de caráter universalista - o Direito Internacional Privado deveria ser o mesmo em todos os Estados, trazendo mais vantagens para as pessoas, destinatárias dessas regras." Porém, com o passar dos anos, os critérios adotados por cada país evoluíram em direções diferentes, e "as grandes diferenças entre as normas adotadas pelos Estados resultaram em uma falta de uniformidade, ao arrepio do que o Direito Internacional Privado necessitava”. (ARAUJO, 2011, p. 43).
} 
uma sentença diversa - e contraditória - em cada um deles; ii) as diferenças entre os sistemas de Direito Internacional Privado pode, em alguns casos, comprometer a eficácia internacional das decisões (impedindo o reconhecimento recíproco de sentenças estrangeiras) e iii) as partes podem promover o chamado forum shopping, buscando beneficiarem-se das diferenças entre os sistemas para buscar a solução que lhes seja mais favorável.

Apesar de os esforços para a uniformização do Direito Internacional Privado terem se reascendido nos últimos anos ${ }^{17}$, ainda não há, no sistema contemporâneo para a solução dos conflitos de leis no espaço, um regramento universal. Assim, na técnica atual, faz-se necessário em primeiro lugar examinar o conflito de jurisdições (qual é o juiz adequado para julgar a causa), pois é o juiz competente quem resolverá, com base no Direito Internacional Privado que lhe é doméstico, a lei aplicável à transação.

Trata-se do exercício necessário para compreender a aplicação dos conceitos à blockchain.

\subsection{CONFLITO DE JURISDIÇÕES NA BLOCKCHAIN}

Segundo Ramos (2018, p. 183), a jurisdição pode ser compreendida em sentido amplo e em sentido estrito. Em sentido amplo, designa o poder do Estado de regência sobre pessoas, bens e entes localizados em seu território. Em sentido estrito, por sua vez, está ligada à atividade do Poder Judiciário na solução das controvérsias que emergem nesse contexto. Trata-se de questão relevante ao Direito Internacional Privado, uma vez que - dado o caráter nacional dos critérios de solução dos conflitos de leis no espaço os métodos da disciplina e os critérios elegidos em cada país para indicação da lei aplicável só serão invocados se o Estado tiver jurisdição internacional para apreciar a disputa em questão ${ }^{18}$.

Como se depreende do seu conceito, a territorialidade é noção diretamente atrelada à ideia de jurisdição: o Estado exerce sua jurisdição nos limites de sua soberania (estabelecidos pelo seu território). Muito antes do advento da tecnologia da blockchain, porém, as Escolas Estatutárias do medievo já reconheciam que certas transações poderiam impactar mais de uma soberania, o que demandaria a necessidade de pensar a jurisdição para além dos estritos limites territoriais (MARINHO; RIBEIRO, 2017, p.

\footnotetext{
${ }^{17}$ Notamente, pelos trabalhos da The Hague Conference on International Private Law.

${ }^{18}$ Relacionando a ideia da jurisdição ao Direito Internacional Público, o Professor Maurice Kamto sustentou que o Direito Internacional requer que o Estado não exceda seus limites jurisdicionais, isto é, ele só pode exercer seus poderes (legislativo, executivo ou judiciário) fora de seu território se houver algum tipo de fator que o conecte a questão, autorizado pelo Direito Internacional. (Fala do Professor Maurice Kamto no General Couse of International Law e Normative Polycentrism no 2021 Winter Course da The Hague Academy of International Law, em 13 de janeiro de 2021).
} 
146). Assim, para além dos fatos ocorridos no território nacional, foram desenvolvidos outros critérios para definição da jurisdição.

É a lei do foro que define os limites para a competência de suas cortes. Isto é: o Direito Processual e o Direito Internacional Privado do país em que a ação foi iniciada é que determinará se ela poderá ser julgada pelas Cortes locais. Embora os países possam ter regras diversas, há, nesse sentido, uma relativa uniformidade. Ao menos, parece claro que um Estado não deve julgar uma disputa sobre a qual não tenha nenhuma ingerência (como, por exemplo, quando nenhuma das partes está domiciliada no Estado ou quando os fatos em que se baseia a disputa foram praticados em outro país ou a obrigação deva ser cumprida alhures) (HASTREITER; WACHOWICZ, 2020).

A título de exemplo, podem-se citar os critérios de competência elencados pelo Direito Brasileiro, nos artigos 21, 22 e 23 do Código de Processo Civil (BRASIL, 2015). Segundo tais disposições, considera-se competente a autoridade judiciária brasileira para apreciar causas em que o réu seja aqui domiciliado, a obrigação deva ser cumprida no Brasil ou o fundamento da ação seja fato ocorrido em território nacional. Ainda, estende-se a jurisdição nacional para as causas de alimentos em que o credor seja aqui domiciliado ou que o réu tenha vínculos econômicos com o Brasil, além das ações decorrentes de relações de consumo cujo consumidor seja domiciliado em território nacional ou quando houver cláusula de eleição de foro nas quais as partes voluntariamente concordaram em se submeter à jurisdição nacional. Por fim, entende-se que apenas a autoridade judiciária brasileira poderá julgar as demandas relativas a imóveis situados no Brasil, bem como as causas sucessórias que envolvam bens situados no Brasil e a partilha de tais bens em caso de dissolução do matrimônio ou da união estável.

A aplicação desses critérios, porém, é problemática no cenário das transações efetivadas via blockchain, pois pode ser difícil - ou até impossível - identificar onde uma criptomoeda está armazenada, onde as transações aconteceram e, até mesmo, onde estão as pessoas envolvidas na atividade (considerando a possibilidade de as transações acontecerem por meio de pseudônimos cuja identidade é preservada). Essa última dificuldade, talvez, seja o maior obstáculo para a adjudicação de disputas oriundas da blockchain pelo Poder Judiciário de um Estado. Isso, porque, dificilmente um Estado poderá considerar juridicamente vinculante e atribuir direitos e deveres em um processo judicial com o réu desconhecido. Ademais, dada a irreversibilidade das transações da blockchain, as decisões judiciais não poderão afetar a realidade do sistema, mas sim as pessoas envolvidas - o que pressupõe que elas devam ser identificadas (GUILLAUME, 2019).

Com a diversificação do uso da tecnologia para outras transações além do comércio de criptomoedas, porém, pode-se pressupor que, muitas vezes, será possível identificar as partes da transação. Nos smartcontracts, por exemplo, a blockchain é usada 
como uma forma de implementação das obrigações de um contrato que existe também no mundo real (e não apenas no virtual) ${ }^{19}$. A insegurança será reduzida se as partes puderem consentir com a jurisdição por meio de uma cláusula de eleição de foro. Naturalmente, se uma das partes for um consumidor, razões de proteção da parte hipossuficiente podem levar à desconsideração da cláusula ${ }^{20}$. Assim, as regras que atrelam a jurisdição ao domicílio do réu, do autor ou do consumidor podem ser alternativas válidas em tais contextos.

Se a Corte, no entanto, interpretar a regra que determina a jurisdição com base no local dos fatos ou do cumprimento da obrigação, poderá chegar a resultados desconcertantes: o fundamento da ação pode ser a existência de um dos "nós" da blockchain em um computador local? Se a resposta for afirmativa, seriam, em tese, todas as cortes onde há computadores com acesso à tecnologia competentes para apreciar as relações celebradas via blockchain (ou seja, virtualmente, todas as cortes do mundo). Como bem explicou Guillaume (2019), é impossível localizar uma transação da blockchain, já que ela se distingue das outras tecnologias justamente por sua arquitetura descentralizada. Não há sequer um servidor central que possa ser usado para estabelecer um local para a informação. Assim, a depender de como se interpreta, a blockchain pode estar em todos os lugares ou em lugar nenhum.

Svantesson $(2017$, p. 3) sintetiza os desafios trazidos pela Internet às regras sobre jurisdição: se as regras de jurisdição forem demasiadamente amplas, podem acabar contemplando condutas com as quais existe um insuficiente nível de contato, gerando uma interferência indevida em assuntos que pertencem à jurisdição de outros Estados e afetando pessoas que não teriam condições adequadas de defesa; por outro lado, se as regras de jurisdição forem muito restritas, há o risco de vítimas ficarem sem remédio judicial para as violações de direitos sofridas (levando à denegação da justiça, que é uma violação de direitos humanos).

Não se pode esquecer, também, que a aceitação de uma Corte quanto a sua competência sobre determinada demanda é apenas o primeiro passo da solução do

\footnotetext{
${ }^{19}$ Lehman destaca neste sentido que a blockchain deve ser entendida como um fato. Na hipótese contratual, como parte da performance esperada em um contrato (e não o contrato em si). Ele exemplifica a obrigação de pagar em bitcoins por um objeto determinado. Nesse caso, seria mais fácil determinar a jurisdição e a lei aplicável com as regras ordinárias do Direito Internacional Privado, pois elas incidiriam sobre um contrato concreto (externo a blockchain) que conteria uma obrigação de fazer (no caso em análise, transferir criptomoedas) que será concretizada (ou não) com os requerimentos da tecnologia. Aceitar as transferências da blockchain como fatos, para o autor, seria a única maneira de conciliá-la com o Direito (LEHMAN, 2019, p. 23 e ss).

${ }^{20}$ Nesse sentido, aduz a legislação brasileira, já que o Marco Civil da Internet, em seu artigo $8^{\circ}$, reputa como nula as cláusulas de eleição de foro em contratos e adesão que impeçam o consumidor de buscarem efetivar seus direitos no Brasil. ("São nulas de pleno direito as cláusulas contratuais que violem o disposto no caput, tais como aquelas que: [...] II - em contrato de adesão, não ofereçam como alternativa ao contratante a adoção do foro brasileiro para solução de controvérsias decorrentes de serviços prestados no Brasil) (BRASIL, 2014, online).
}

71• R. Opin. Jur., Fortaleza, ano 20, n. 33, p.60-82, jan./abr. 2022 
"quebra-cabeças" das transações virtuais, sendo ainda necessário observar o conflito de leis. A possibilidade de propor a ação em múltiplas jurisdições diferentes - todas igualmente competentes - torna a escolha da lei aplicável questão ainda mais importante: bem assessorada, uma parte poderia eleger o local de propositura da ação com base justamente no Direito Internacional Privado de cada local - selecionando a dedo a Corte que considerará aplicável o Direito que lhe for mais favorável.

\subsection{CONFLITO DE LEIS NA BLOCKCHAIN}

Se o juiz para quem a demanda foi apresentada entender que a causa está dentro de seus limites jurisdicionais, o próximo passo na técnica do Direito Internacional Privado é buscar qual o Direito aplicável para solucionar a questão material apresentada. Isso acontecerá através das normas indicativas de Direito Internacional Privado, as quais, ao invés de regular diretamente o fato transnacional, indicam a norma responsável por sua regência (RAMOS, 2018). Tais normas possuem uma estrutura típica, composta sempre por duas partes distintas: o objeto de conexão - que versa sobre a matéria regulada pela norma conflitual (ex. contratual, sucessões, direitos reais, etc) - e o elemento de conexão - que funciona como elemento de localização do direito aplicável, identificando qual o fator ao qual se atribuir maior proximidade com um determinado sistema jurídico (o domicílio, o local do bem ou do ilícito, etc) (MAZZUOLI, 2017).

O processo pelo qual os fatos narrados na demanda são enquadrados nas categorias jurídicas descritas pelos objetos de conexão é denominado de qualificação (RAMOS, 2018). No entanto, qualificar uma relação jurídica celebrada pela blockchain e rotulá-la em uma destas categorias pode ser desafiador. Sequer seria possível estabelecer tal qualificação genericamente, em razão das múltiplas possibilidades de relações a serem efetivadas por intermédio da tecnologia. Partindo de sua aplicação tradicional - as criptomoedas - a dificuldade de qualificação torna-se bastante visível.

Uma transação que envolve a transferência de uma criptomoeda contempla tanto o elemento obrigacional (um contrato de compra e venda) como reúne os atributos necessários a ser inserida como uma relação de propriedade sobre bens (inserindo-se, assim, na seara dos Direitos Reais). Para conciliar o Direito Internacional Privado às criptomoedas, segundo Lehman, o fundamental seria não discutir a questão sob o prisma dos Direitos reais ${ }^{21}$, mas aceitar as transações feitas na blockchain como fatos

\footnotetext{
${ }^{21}$ Para o autor, haveria uma crença de que os direitos dos detentores de ativos virtuais só seriam protegidos por meio do enquadramento da relação como direitos reais. No entanto, a proteção pode acontecer sem a existência de um título legal a reconhecendo (LEHMAN, 2019, p. 27).
} 
cujos resultados não mais podem ser alterados ${ }^{22}$ e buscar no Direito obrigacional os remédios cabíveis.

Isso porque, nos Direitos Reais, o elemento de conexão clássico é o lex rei sitae (o local onde o bem está). Determinar o local onde o "bem" se encontra é impossível no caso da blockchain. Uma criptomoeda não tem existência real, apenas um registro virtual, feito em um livro-razão que está distribuído em diversos computadores ao redor do mundo ao mesmo tempo (LEHMAN, 2019).

Se não é possível identificar a lei do local do bem, restaria ao Direito Internacional Privado tentar localizar a lei aplicável aos contratos, às relações obrigacionais fruto de ilícitos e, até, às questões sucessórias que têm como elemento fático a existência de ativos transferidos por meio da tecnologia blockchain. No entanto, essa posição traz impactos que podem recair sobre o resultado substancial da demanda. Se uma pessoa "A" transferiu uma criptomoeda para a pessoa "B" como resultado de um erro, dolo ou fraude, a abordagem da blockchain como fato impediria que se buscasse invalidar a transação. Nesse caso, o enfoque, segundo Lehman (2019), deveria recair sobre a possibilidade de reverter as transações na própria blockchain - o que pode ser ordenado pelo Direito por meio de uma obrigação de fazer uma transferência reversa, garantida pela aplicação de multas em caso de descumprimento.

Isso porque as criptomoedas são bens fungíveis que atuam como meios de pagamento (LEHMAN, 2019). Não caberia ao Direito, portanto, inserir a temática sob o prisma dos Direitos reais e verificar a validade do título de um detentor de uma determinada criptomoeda para saber se ele poderia ou não a transferir. A blockchain é o sistema de registro que dá validade às transações - e isso precisa ser reconhecido como fato pelo Direito, sob pena inclusive de tornar a tecnologia inútil ${ }^{23}$. Isso não significa, porém, que a alocação de direitos estabelecida pela blockchain deva ser a final, especialmente se esse resultado se mostrar contrário às exigências do Direito que lhe é aplicável.

Concordando com Lehman (2019), Guillaume (2019) também afirma que o local do bem não é um critério razoável para a blockchain. Para ele, ainda que fosse possível identificar o local onde a carteira virtual com criptomoedas se encontra, tal local seria muito aleatório para servir ao propósito de um elemento de conexão. No entanto, a

\footnotetext{
${ }^{22}$ Nesse sentido, afirma "The law cannot undo a fact, but it can provide remedies aiming to reverse the situation that had been achieved. What comes to the fore here is the difference between a set of facts and a normative order. The law as a normative order cannot undo a fact, e.g. a tort that has been committed, a document that has been handed over or work that has been performed. Yet it can remedy the consequences of these facts with hindsight. Just as the effects of an unjust enrichment can be compensated by a restitution claim, the law can impose an obligation on the recipient of virtual assets recorded on the blockchain to return what has been received (LEHMAN, 2019, p. 21).

${ }^{23} \mathrm{Um}$ livro caro de registros sem função prática, já que o Direito estaria questionando e revalidando cada uma das transações per se (LEHMAN, 2019, p. 19).
} 
solução de encarar as transações na blockchain como fatos e buscar remédios no Direito obrigacional não é aceita de modo unânime na doutrina. O próprio Lehman (2019) encontra problemas no uso do direito obrigacional em determinadas circunstâncias por exemplo, o roubo de uma criptomoeda efetuado por um hacker. O autor reconhece que o Direito obrigacional não forneceria remédio suficiente nestes casos, porque, se o hacker que roubou o acesso a uma criptomoeda se tornar insolvente, a mera obrigação de re-transferir a moeda a quem a teve indevidamente retirada seria constituída como um crédito simples, sujeito a toda a ordem de preferência no processo de satisfação dos credores, sem qualquer garantia. Outros credores inclusive se beneficiariam da manobra ilegal do hacker, que teria aumentado seu patrimônio. Nesse caso, a única maneira de evitar este resultado seria considerar que o hacker não dispunha da propriedade da criptomoeda em primeiro lugar. Isto é: analisar a validade do título sob a ótica dos Direitos Reais.

Outro ponto de vista é sustentado por NG (2019), que analisa a questão sob o prisma da common law inglesa. $\mathrm{O}$ autor defende que, para a finalidade de qualificar a transação no Direito Internacional Privado britânico, seria necessário reconhecer a criptomoeda como um bem e, então, buscar a lei que lhe é aplicável (ius in rem) ${ }^{24}$. No entanto, o autor sustenta que as criptomoedas são uma forma sui generis de propriedade - que não se assemelha a nenhuma outra forma de bens intangiveis - e que, portanto, requereria novas formas para determinação de sua localização. Em sua proposta, tal elemento de conexão deveria ser o da lei com maior conexão à rede de blockchain na qual a criptomoeda estaria inserida. Nesse caso, a questão retornaria à abordagem contratual, ainda que indiretamente.

No que tange aos contratos, o elemento de conexão mais empregado internacionalmente é o da lex voluntatis ${ }^{25}$, isto é, a lei aplicável aos contratos seria aquela escolhida aos contratantes, consagrando o princípio da autonomia da vontade. Em tese, as partes poderiam escolher a lei aplicável numa transação realizada pela blockchain de duas formas: com uma cláusula de escolha da lei em um contrato paralelo (cujo smartcontract atuaria apenas como garantidor da performance) ou com a inclusão da

\footnotetext{
${ }^{24} \mathrm{~A}$ analogia, nesse caso, seria com a propriedade intelectual, na qual o Direito britânico reconhece como matéria de Direitos reais para o propósito de determinar o direito aplicável, ainda que não seja questão regulada na seara dos Direitos reais pelo direito substancial. NG, Michael. Choice of Law for property issues regarding bitcoin under English Law. Journal of Private International Law, 15:2, 315 338. Disponível em: https://doi.org/10.1080/17441048.2019.1649235. Acesso em: 12 jan. 2021, p. 321.

${ }^{25}$ Trata-se, por exemplo, do elemento de conexão previsto no artigo $3^{\circ}$ do Regulamento de Roma I, que rege os contratos internacionais na União Europeia. UNIÃO EUROPEIA. REGULAMENTO CE N® 593/2008 do Parlamento Europeu e do Conselho de 17 de junho de 2008 sobre a lei aplicável as obrigações contratuais (Roma I). Jornal Oficial da União Europeia. 4.7.2008. Disponível em: https://eur-lex.europa.eu/legal-content/PT/TXT/PDF/?uri=CELEX:32008R0593\&from=PT. Acesso em: 15 jan. 2021.
} 
escolha da lei aplicável em sua programação. RUHL (2020), no entanto, questiona se uma cláusula de escolha da lei aplicável pode ser redigida no formato algorítmico (se $\mathrm{X}$, então Y). Lehman (2019), por sua vez, afirma que seria pouco provável que o código de um sistema de criptomoedas, por exemplo, contemplasse a escolha de alguma lei estatal para reger suas transações, dado o caráter filosófico anti-Direito expressado pela tecnologia.

Nesse caso, a escolha da lei aplicável teria de ocorrer por meio de um contrato paralelo. É possível estabelecer tal contrato sob a forma de um "contrato ricardiano" 26 isto é, um contrato que combina a linguagem natural e a digital e é registrado em um documento que pode tanto ser lido por humanos quanto por computadores, armazenado em um sistema online seguro (RUHL, 2020).

Questão mais problemática se dá, porém, se as partes não escolheram a lei aplicável ao contrato $^{27}$ ou, como é o caso no Brasil, quando o sistema de Direito Internacional Privado do foro não reconhece às partes contratantes o direito de escolherem a lei para reger o contrato ${ }^{28}$. O critério do lex loci celebracionis (lei do local de celebração) é frequentemente adotado nesses $\operatorname{casos}^{29}$. Contudo, precisar qual a localização de um contrato eletrônico é tarefa difícil e que se torna ainda mais complexa na lógica dos sistemas descentralizados da blockchain. $\mathrm{O}$ critério adotado pelo direito brasileiro para os casos de contratos celebrados entre ausentes pode, nas Cortes locais, ser invocado: nesses casos, aplica-se a lei do local de residência da pessoa que fez a

\footnotetext{
${ }^{26}$ Originalmente, os contratos ricardianos consistiam em métodos de registro de documentos em sistemas informatizados. Trata-se de uma tecnologia inventada por Ian Grigg em 1996. Sobre o tema, ver em: CREIMER, Marcelo. Contratos Ricardianos em Blockchain. Disponível em: https://www.blockmaster.com.br/artigos/contratos-ricardianos-em-blockchain/. Acesso em: 16 jan. 2021.

${ }^{27}$ No Direito europeu, a escolha pode ser presumida. Se isso não for possível, deve-se buscar o local com a conexão mais próxima (artigo $4^{\circ}$ do Regulamento de Roma I) UNIÃO EUROPEIA. REGUlAMENTO CE N® 593/2008 do Parlamento Europeu e do Conselho de 17 de junho de 2008 sobre a lei aplicável as obrigações contratuais (Roma I). Jornal Oficial da União Europeia. 4.7.2008. Disponivel em: https://eur-lex.europa.eu/legalcontent/PT/TXT/PDF/?uri=CELEX:32008R0593\& from=PT. Acesso em: 15 jan. 2021.

${ }^{28}$ Há, sobre o tema, muito debate. Na realidade, a Introdução ao Código Civil de 1916 previa a possibilidade de as partes escolherem a lei que rege seus contratos, ao afirmar que a lei do lugar da celebração do contrato regularia o conteúdo e os efeitos das obrigações, "salvo disposição em contrário". No entanto, o Decreto Lei 4.657/1942 (atualmente denominada a Lei de Introdução às normas do Direito brasileiro) trouxe o artigo $9^{\circ}$ (até hoje, vigente) que estabelece que, "para qualificar e reger as obrigações, aplicar-se-á a lei do país em que se constituírem". A expressão "salvo disposição em contrário", presente no diploma anterior, foi excluída em razão da visão desconfiada quanto à autonomia privada na Era Vargas. A doutrina dominante, no Brasil, entende que o artigo $9^{\circ}$ da LINDB é uma norma cogente e que, como tal, não pode ser derrogada pela vontade das partes. Assim, não existiria espaço para a escolha da lei aplicável. Nesse sentido, ver em: Ramos (2018, p. 413) e Brasil (1942).

${ }^{29}$ Trata-se da previsão constante na LINDB, conforme N.R supra e também do previsto no Código Bustamente (Convenção de Direito Internacional Privado de 1928), em seu artigo 186. Disponível em: Brasil (1929).
} 
proposta do contrato $^{30}$. A tarefa consistiria em identificar qual das duas partes envolvidas na transação poderia ser enquadrada como proponente, para, então, considerar a lei de seu domicílio como aplicável ao contrato internacional. Novamente, dificuldades emergiriam caso as partes estivessem atuando a partir de pseudônimos, em transações anônimas.

Dadas as dificuldades trazidas pela tecnologia, somada a uma incompreensão de seus principais postulados pelos operadores do Direito, é possível que as Cortes também decidam pelo caminho mais fácil: a aplicação da lex fori, isto é, aplicar a lei nacional as demandas apreciadas pelas Cortes locais. Tal proposta foi adotada pelo Principado de Mônaco, que atualmente discute uma lei para regular as transações na blockchain. $\mathrm{Na}$ propositura, consta a previsão de aplicação das regras em elaboração para toda e qualquer disputa envolvendo a blockchain que seja apresentada às Cortes locais (GUILLAUME, 2019). O risco, porém, é o de que a disseminação deste critério contribua à prática do fórum shopping, isto é, a possibilidade de escolher a Corte para propor a ação com base na análise de qual jurisdição nacional the daria melhores chances de vencer a demanda (RUHL, 2020).

As dificuldades supracitadas fazem que nem todos os autores concordem que os elementos de conexão tradicionais sejam capazes de resolver a questão. Para Wright e De Filippi (2015), assim como para GUILLAUME (2019), o caminho para resolver o imbróglio está no desenvolvimento da chamada "lex cryptographia": uma espécie de autorregulação similar à lex mercatória ${ }^{31}$ que poderia emergir a partir das práticas e dos costumes dos participantes da blockchain. A aplicação dessas regras poderia ser complementada por sistemas que acompanhem a lógica virtual, como os mecanismos Online Disputes Resolution (ODR) (GUILLAUME, 2019).

Parece, no entanto, haver uma relativa unanimidade quanto a uma questão: a existência de diferentes regras de Direito Internacional Privado ao redor do mundo torna o cenário ainda mais nebuloso. Se os Estados adotassem, ao menos, a mesma regra de Direito Internacional Privado, todo o sistema se beneficiaria com um acréscimo de segurança jurídica às transações. Sobre esse tema em particular, o Direito pode se beneficiar das lições obtidas da tecnologia blockchain.

\footnotetext{
${ }^{30}$ Conforme artigo $9^{\circ}$, parágrafo $2^{\circ}$, da LINDB. (BRASIL, 1942).

${ }^{31}$ Segundo André de Carvalho Ramos, "originalmente a lex mercatória consistia em normas e estruturas de regulação de contratos e temas de circulação de mercadorias, criadas por comerciantes marítimos e terrestres na Baixa Idade Média e de parte da Idade Moderna europeia. Em um momento de busca de segurança jurídica e ausência de um poder estatal centralizado, a lex mercatória medieval era formada pelos estatutos das corporações, costumes mercantis e decisões das jurisdições mercantis. Já na segunda metade do século XX, a doutrina adota o conceito de nova lex mercatória para simbolizar a importância da prática dos negócios internacionais e da jurisprudência arbitral comercial para reger os negócios internacionais”. (RAMOS, 2018, p. 123).
} 


\section{O CONFLITO DE LEIS E JURISDIÇÕES SOB A ÓTICA DE UMA GOVERNANÇA PEER TO PEER}

Para Mills (2014), o Direito Internacional Privado deveria ser compreendido como o ramo do Direito encarregado de solucionar problemas de governança internacionais, definindo qual a autoridade reguladora para os temas que transcendem as fronteiras de um Estado. Com a crescente integração da sociedade internacional e a emergência de temas profundamente cosmopolitas - como a blockchain - cada vez mais, esse ramo do Direito é conclamado a assumir um papel semelhante ao da distribuição de competências nas Constituições de sistemas federativos ${ }^{32}$.

No entanto, a sociedade internacional não dispõe das mesmas ferramentas dos sistemas federativos para sua coordenação: notadamente, carece de estruturas hierárquicas, dada a inexistência de instituições governamentais globais capazes de uniformizar efetivamente e monitorar a internacionalização do Direito Internacional Privado $^{33}$. Ainda, subsiste o problema da nacionalização da disciplina, com cada país adotando suas próprias normas solucionadoras dos conflitos de leis no espaço.

Para assumir esse papel de coordenação das diferentes ordens jurídicas nacionais, o Direito Internacional Privado precisa, de fato, da universalização dos seus postulados, como já era proposto na ideia original de Savigny. Nesse sentido, instituições como a The Hague Conference on International Private Law se esforçam para elaborar regras modelo de Direito Internacional Privado, mas carecem de instituições de monitoramento e aplicação capazes de garantir sua concretização.

Trata-se, assim, de uma retomada da questão da governança já abordada no início deste $\operatorname{artigo}^{34}$. As estruturas hierárquicas, no entanto, são ausentes no cenário internacional, e não há perspectiva de desenvolvimento próximo de mecanismos supranacionais que se assemelhem aos governos domésticos para exercer este papel. Ao compreender a blockchain e as redes peer to peer como uma nova possibilidade de arranjo institucional, o espectro de possibilidades de estruturas de governança aumenta e pode apontar caminhos à disciplina.

\footnotetext{
${ }^{32}$ Nesse sentido, o autor destaca o papel da disciplina no Direito europeu, no qual o Direito Internacional Privado tem se tornado muito mais uma ferramenta para lidar com o pluralismo jurídico, do que simplesmente uma questão técnica do processo civil. (MILLS, 2014, p. 250).

${ }^{33} \mathrm{Em}$ seu texto, Alex Mills levanta algumas possibilidades, sugerindo até mesmo que a Corte Internacional de Justiça fizesse as vezes de tribunal constitucional para monitorar a aplicação das normas de Direito Internacional Privado. A hipótese já foi sugerida no caso Belgium vs. Switzerland sobre a aplicação da Convenção de Lugano sobre jurisdição e aplicação de decisões estrangeiras em matérias civis e comerciais. As partes, no entanto, chegaram a um acordo antes que a questão fosse decidida pela CIJ. ICJ, Jurisdiction and Enforcement of Judgments in Civil and Commercial Matters (Belgium v. Switzerland). Disponível em: https://www.icj-cij.org/en/case/145. Acesso em: 16 jan. 2021.

${ }^{34}$ Ver, no item 1, discussão tradicionalmente trazida por Williamson (1985).
} 
As redes peer to peer podem fornecer um desenho para o arranjo institucional adequado à internacionalização das normas solucionadoras de conflitos de leis e jurisdições, ao demonstrar como estruturas horizontais podem funcionar de modo coordenado, sem suporte institucional, promovendo, ainda assim, uma organização necessária para o estabelecimento de regras comuns (MILLS, 2014). Dessa forma os Estados podem se inserir em uma espécie de organização peer to peer para uniformizar as regras de conflitos de leis e jurisdições, com os organismos de Direito Internacional Privado atuando de modo análogo aos mecanismos de autorregulação da Internet (como a Internet Governance Forum, a Internet Engineering Task Force e a Internet Society) e elaborando diretrizes e leis modelos que, posteriormente, serão monitorados através de um sistema horizontal de cooperação entre os Estados.

A elaboração de normas uniformes e o seu monitoramento pelos pares pode ser uma possibilidade da lógica da blockchain concretizar, ainda que dois séculos mais tarde, o ideal universalizante de Savigny quanto às normas indiretas de Direito Internacional Privado. Se isso for possível, inclusive as transações na própria blockchain, ganharão em segurança jurídica, sendo possível responder a priori qual a lei aplicável à transação, a despeito da incerteza sobre qual Corte nacional resolveria a questão.

\section{CONSIDERAÇÕES FINAIS}

Este trabalho buscou demonstrar como a descentralização das redes de "nós" envolvidos na tecnologia blockchain trazem dificuldades na aplicação dos critérios de solução de conflitos de leis e jurisdições do Direito Internacional Privado. Isso porque os postulados tradicionais da disciplina pautam-se na ideia de localizar a relação jurídica no espaço, e as transações celebradas na blockchain podem estar em todos os lugares, ou em lugar algum, a depender de como se interpreta.

O trabalho demonstrou, porém, que alguns critérios clássicos do Direito Internacional Privado podem ser aplicados às transações realizadas por meio da tecnologia - ao menos, na maior parte das situações. Quando as partes são identificadas e realizaram um smart contract para efetivar obrigações de um contrato principal, as regras aplicáveis aos contratos internacionais podem ser invocadas sem maiores esforços hermenêuticos.

A diversidade de Cortes competentes para apreciar questões oriundas da tecnologia descentralizada, porém, traz preocupações significativas em razão da falta de uniformidade entre os critérios solucionadores de conflitos de leis no espaço no mundo. A depender de onde a ação foi proposta, uma regra diferente de Direito poderá ser aplicada. O cenário traz insegurança jurídica e favorece manobras como a do fórum shopping, em que as partes podem beneficiar-se dos diferentes critérios legais para eleger 
o foro da disputa a partir da identificação do local que trará o melhor conjunto de regras aplicáveis.

A situação gera incertezas, o que não favorece um comportamento cooperativo e espontâneo de conformidade ao Direito pelas partes - afinal, qual o Direito com o qual as partes devem se conformar? Além disso, o cenário também parece incondizente com as exigências de justiça, já que a possibilidade de múltiplas respostas para as mesmas questões jurídicas é uma evidente ferramenta para a produção de inequidades.

O trabalho, então, sugere que o modelo institucional peer to peer possa servir de exemplo e abrir um caminho para a unificação do Direito Internacional Privado. Tratase de uma analogia, não se pretendendo aqui sustentar que alguma forma de inteligência artificial possa suplantar o debate público e o das instituições competentes na escolha dos melhores critérios para solução do conflito de leis no espaço. $\mathrm{O}$ arranjo demonstra, porém, que é possível uma solução cooperada em relações horizontais, sem a presença de um elemento hierárquico - como um grande Leviatã internacional.

Assim, ao mesmo tempo em que a tecnologia blockchain precisa do Direito Internacional Privado para encontrar a resposta ao conflito de leis que ela contém, ela também parece fazer um convite a esse ramo do Direito para atualizar seus postulados e uniformizar suas soluções diante da inevitável revolução tecnológica que desafia os limites e as fronteiras estabelecidos no espaço geográfico.

\section{REFERÊNCIAS}

ARAUJO, Nádia de. Direito Internacional Privado: teoria e prática brasileira. 5. ed. Atualizada e a ampliada. Rio de Janeiro: Renovar, 2011.

BRASIL. Decreto ${ }^{\circ} 18.871$ de 13 de agosto de 1929 - Convenção de Direito Internacional Privado, de Havana. Disponível em: https://www2.camara.leg.br/legin/fed/decret/1920-1929/decreto-18871-13-agosto1929-549000-publicacaooriginal-64246-pe.html. Acesso em: 16 jan. 2021.

BRASIL. Decreto-Lei ${ }^{\circ} 4.657$ de 04 de setembro de 1942. Brasília, DF: Presidência da República, 1942. Disponível em: http://www.planalto.gov.br/ccivil_03/decretolei/del4657 compilado.htm. Acesso em: 16 jan. 2021.

BRASIL. Lei $\mathrm{n}^{\circ} 12.965$ de 23 de abril de 2014. Brasília, DF: Presidência da República, 2014. Disponível em: http://www.planalto.gov.br/ccivil_03/_ato20112014/2014/lei/112965.htm. Acesso em: 15 jan. 2021.

BRASIL. Lei no 13.105 de 16 de março de 2015 - Código de Processo Civil. Brasília,
DF:
Presidência
da República,
2015.
Disponível
em: 
http://www.planalto.gov.br/ccivil_03/_ato2015-2018/2015/lei/113105.htm. Acesso em: 14 jan. 2021.

GUILLAUME, Florence. Aspects of private international law related to blackchain transactions. In: KRAUS, Daniel; THIERRY, Obrist; OLIVIER, Hari. Blockchains. Smart contracts, decentralized autonomous. Organizations and the Law. Cheltenham/Northampton: Edward Elgar Publishing, 2019. p. 49-82.

HASTREITER, Michele Alessandra; WACHOWICZ, Marcos. Derechos de autor y Derecho Internacional Privado: la necesaria superación del paradigma de la territorialidad en la sociedade informacional. In: TERLIZZI, María Sol; WACHOWICZ, Marcos. Propriedad Intelectual, Sociedad y Desarollo. Reflexiones desde Latinoamérica. Ciudad Autónoma de Buenos Aires: Flacso Argentina; Curitiba: GEDAI-UFPR, 2020.

ICJ. Jurisdiction and Enforcement of Judgments in Civil and Commercial Matters (Belgium v. Switzerland). Disponível em: https://www.icj-cij.org/en/case/145. Acesso em: 16 jan. 2021.

IRIS. Blockchain and e-Government: the Estonian experience and the first Brazilian initiatives. Disponível em: https://irisbh.com.br/en/blockchain-and-e-government-theestonian-experience-and-the-first-brazilian-initiatives/. Acesso em: 5 jan. 2020.

KAMTO, Maurice. International Law and Normative Polycentrism (lecture). The Hague Academy of International Law, 2021 Online Winter Course, 13 de janeiro de 2021.

LEHMANN, Matthias. Who owns bitcoin? Private Law Facing the Blockchain. 21 MinN. J.L. SCI. \& TeCH., 21, n. 1, 2019. Disponível em: https://scholarship.law.umn.edu/mjlst/vol21/iss1/4. Acesso em: 6 dez. 2020.

LESSIG, Lawrence. Code - version 2.0. New York: Basic books, 2006.

MARINHO, Maria Edelvacy Pinto; RIBEIRO, Gustavo Ferreira. A reconstrução da jurisdição pelo espaço digital: redes sociais, blockchain e criptomoedas como propulsores da mudança. Revista Brasileira de Políticas Públicas, Brasília, v. 7, n. 3, p. 146, 2017.

MAZZUOLI, Valério de Oliveira. Curso de Direito Internacional Privado. 2. ed. São Paulo: Forense, 2017.

MILLS, Alex. Variable Geometry, Peer Governance and the Public International Perspective on Private International Law. In: MUIR WATT, Horatia; ARROYO, Diego. Private International Law and Global Governance. Oxford: Oxford University Press, 2014. 
NG, Michael. Choice of Law for property issues regarding bitcoin under English Law. Journal of Private International Law, v. 15, n. 2, p. 315-338, 2019. Disponivel em: https://doi.org/10.1080/17441048.2019.1649235. Acesso em: 12 jan. 2021.

NORTH, Douglass C. Economic Performance Through Time. The American Economic Review, v. 84, n. 3, 1994.

RAMOS, André de Carvalho. Curso de Direito Internacional Privado. São Paulo: Saraiva, 2018.

RUHL, Giesela. Smart (legal) contracts or: which (contract) law for smart contracts? In: CAPPIELlO, Benedetta; CARULLO, Gherardo. Blockchain, Law and Governance. [S.l.]: Springer, 2020.

RULH, Giesela. Methods and Approaches in Choice of Law: an Economic Perspective. Berkeley. Journal of International Law, v. 24, n. 3, 2006. Disponível em: http://scholarship.law.berkeley.edu/bjil/vol24/iss3/2. Acesso em: 16 jan. 2021.

SAVELYEV, Alexander. Contract Law 2.0: <<Smart〉> Contracts as the beginning of the end of Classic Contract Law. Higher School of Economics Research Paper No., 2016. Disponível em: https://papers.ssrn.com/sol3/papers.cfm?abstract_id=2885241. Acesso em: 12 jan. 2020.

SAVIGNY, Friedrich Carl Von. Sistema do Direito Romano Atual - Volume VIII Introdução de Erik Jayme. Coleção clássicos do Direito Internacional. Tradução de Ciro Mioranza. Ijuí: Ed. Unijuí, 2004

SINCLAIR, Davidson; DE FILIPPII, Primavera; POTTS, Jason. Disrupting governance: The new institutional economics of distributed ledger technology. 2016. Disponível em: https://papers.ssrn.com/sol3/papers.cfm?abstract_id=2811995. Acesso em: 7 out. 2019.

SVANTESSON, Dan Jerker B. Solving the Internet Jurisdiction Puzzle. Oxford: Oxford University Press, 2017.

TAPSCOTT, D.; TAPSCOTT, A. Blockchain Revolution. New York: Penguin, 2016.

UNIÃO EUROPEIA. Regulamento CE No 593/2008 do Parlamento Europeu e do Conselho de 17 de junho de 2008 sobre a lei aplicável as obrigações contratuais (Roma I). Jornal Oficial da União Europeia. 4.7.2008. Disponível em: https://eurlex.europa.eu/legal-content/PT/TXT/PDF/?uri=CELEX:32008R0593\&from=PT.

Acesso em: 15 jan. 2021. 
WILLIAMSON, Oliver. Transaction Cost Economics, in The Economic Institutions of Capitalism. New York: The Free Press, 1985.

WRIGHT, Aaron; DE FILIPPI, Primavera. Decentralized Blockchain Technology and the rise of Lex cryptofraphia. 2015. Disponível em: https://papers.ssrn.com/sol3/papers.cfm?abstract_id=2580664. Acesso em: 16 jan. 2021.

\section{NOTA}

Declaramos, para os devidos fins, que o artigo de título CONFLITOS DE LEIS E JURISDIÇÕES NAS TRANSAÇÕES CELEBRADAS A PARTIR DA BLOCKCHAIN foi redigido em co-autoria por Michele Alessandra Hastreiter e Marcia Carla Pereira Ribeiro. A pesquisa é parte da tese de doutoramento de Michele Hastreiter, que estuda os conflitos de leis e jurisdições nas relações jurídicas virtuais. $\mathrm{O}$ trabalho é orientado pela Professora Márcia Carla Ribeiro, que contribuiu especialmente com aportes da análise econômica do Direito ao desenvolvimento deste artigo.

Como citar este documento:

HASTREITER, Michele Alessandra; RIBEIRO, Marcia Carla Pereira. Conflitos de leis e jurisdições nas transações celebradas a partir da blockchain. Revista Opinião Jurídica, Fortaleza, v. 20, n. 33, p. 60-82, jan./abr. 2022. 